\title{
A Participatory GIS Approach for Assessing Land Suitability for Rainwater Harvesting in an Arid Rangeland Environment
}

\author{
Feras Ziadat , Adriana Bruggeman, Theib Oweis , Nasri Haddad, Safa \\ Mazahreh, Wael Sartawi \& Maha Syuof
}

To cite this article: Feras Ziadat, Adriana Bruggeman , Theib Oweis , Nasri Haddad, Safa Mazahreh , Wael Sartawi \& Maha Syuof (2012) A Participatory GIS Approach for Assessing Land Suitability for Rainwater Harvesting in an Arid Rangeland Environment, Arid Land Research and Management, 26:4, 297-311, DOI: 10.1080/15324982.2012.709214

To link to this article: http://dx.doi.org/10.1080/15324982.2012.709214

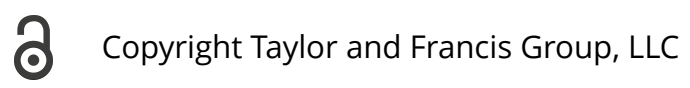

\section{Published online: 19 Sep 2012.}

Submit your article to this journal ¿

III Article views: 2112

Q View related articles $\sqsubset$

Citing articles: 9 View citing articles 


\title{
A Participatory GIS Approach for Assessing Land Suitability for Rainwater Harvesting in an Arid Rangeland Environment
}

\author{
Feras Ziadat ${ }^{1,2}$, Adriana Bruggeman ${ }^{3}$, Theib Oweis ${ }^{1}$, \\ Nasri Haddad $^{1,2}$, Safa Mazahreh ${ }^{4}$, Wael Sartawi ${ }^{5}$, and \\ Maha Syuof ${ }^{4}$ \\ ${ }^{1}$ International Center for Agricultural Research in the Dry Areas \\ (ICARDA), Aleppo, Syrian Arab Republic \\ ${ }^{2}$ Faculty of Agriculture, University of Jordan, Amman, Jordan \\ ${ }^{3}$ Hydrology and Water Management, Energy, Environment and Water \\ Research Center (EEWRC), The Cyprus Institute, Nicosia, Cyprus \\ ${ }^{4}$ National Center for Agricultural Research and Extension (NCARE), \\ Baqaa, Jordan \\ ${ }^{5}$ Department of Land and Irrigation, Ministry of Agriculture, Amman, \\ Jordan
}

\begin{abstract}
The dry rangelands of West Asia and North Africa are fragile and severely degraded due to low rainfall and mismanagement of natural resources. Rainwater harvesting $(R W H)$ interventions are used to increase soil moisture content, vegetation cover, and productivity. However, adoption of rainwater harvesting by communities is slow. To understand adoption constraints and to develop options for sustainable integration of rainwater harvesting, a benchmark watershed was established in the dry rangelands of Jordan. The objective is to develop a methodology for identifying the suitability for different rainwater harvesting interventions using participatory GIS approach and field survey. The main biophysical parameters used to assess the suitability for rainwater harvesting were slope, soil depth, soil texture, and stoniness. Criteria for each parameter were integrated and a suitability map was produced using raster-based and polygon-based analysis. To integrate biophysical and socio-economic aspects, the land tenure was superimposed with the suitability map. Options for implementing different rainwater harvesting interventions were identified with the participation of the local communities. Field investigations indicated that the applied approach helped to select the most promising fields. Within two years, four types of rainwater harvesting were implemented in the fields of 41 farmers, covering 62.9 hectares, which helped to increase water productivity
\end{abstract}

Received 22 September 2010; accepted 3 March 2012.

The authors would like to acknowledge the financial support obtained from the International Fund for Agricultural Development (IFAD) and the Arab Fund for Economic and Social Development (AFESD). Also, thanks are due to Khalid Al-Zubaidi, Emad Karablieh, Bogachan Benli, Mohfooz Abu Zanat, Jawad Al-Bakri, Akhtar Ali, Douki Al-Hunaiti, Khalil Salameh, Khaleel Abu-Swai, Mona Saba, Khalil Jamjoum, and Ahmad Amri for their valuable contributions.

Address correspondence to Feras Ziadat, International Center for Agricultural Research in the Dry Areas (ICARDA), P.O. Box 5466, Aleppo, Syria; Fax: +(963-21) 2213490. E-mail: f.ziadat@cgiar.org 
$\left(\mathrm{kg} / \mathrm{m}^{3}\right)$ four folds and reducing soil erosion five folds compared to fields without rainwater harvesting. The approach showed that participatory GIS approach may be used to integrate socio-economic and biophysical criteria and facilitate the participation of farmers to introduce rainwater harvesting interventions in dry rangeland systems to mitigate land degradation.

Keywords benchmark watershed, biophysical suitability, land tenure, approach, participatory GIS multidisciplinary, socio-economic suitability

The world's arid and semi-arid zones cover around 50 million $\mathrm{km}^{2}$, which represents $35 \%$ of the earth's land surface (Livingstone, 1985). These areas support a large portion of the world's population and are increasingly used for agricultural production to satisfy the increased food demand of the growing population (Reynolds and Smith, 2007; Tewari and Ranjana, 2005, FAO, 1983). The low and highly variable rainfall is often inadequate for economic crop production; therefore, water is the most limiting resource to improve agricultural production (Oweis et al., 2006; Tsubo et al., 2005).

The arid lands of West Asia and North Africa (WANA) are the grazing grounds of the flocks of sheep, goats, and camels of the Bedouin and are known as al badia in the Middle East region. Average annual rainfall ranges between 50 and $250 \mathrm{~mm}$. The arid area (al badia) covers large parts of the region-around $80 \%$ of Jordan, $75 \%$ of Iraq, $90 \%$ of Saudi Arabia, and 55\% of Syria (Sankari, 1993) - and is mainly used for livestock grazing (Haddad, 2006). Rainwater is generally poorly managed and, despite its scarcity, large quantities are lost through evaporation and runoff. To improve production in these areas, it is necessary to sustainably manage the natural resources-land and water (FAO, 1983). The challenge is how to enhance productivity and halt land degradation in these marginal environments (Oweis et al., 2006).

Rainwater harvesting is the concentration and collection of surface runoff from catchments for agricultural and domestic purposes. It can improve the productivity of rainwater and maintain productive and sustainable agro-pastoral systems in marginal environments (Prinz et al., 1998; Van Wesemael et al., 1998). It could also control soil erosion and reduce the impact of drought (Oweis et al., 2006). During the last two decades, the potential of rainwater harvesting to mitigate the variability of rainfall (spatially and temporally) becomes very obvious (Mwenge Kahinda et al., 2008).

Rainwater harvesting has been used for thousands of years in arid and semi-arid regions of the world to supplement scarce water resources (Hamadeh et al., 1999). The successful performance of indigenous rainwater harvesting systems in the arid area of Jordan (al badia) has been documented by various researchers (Taimeh and Hattar, 2001; Oweis and Taimeh, 1996). However, rainwater harvesting technologies are not widely implemented by the communities who live in this arid area (De Pauw et al., 2006; Critchley et al., 1992).

\section{Land Suitability for Rainwater Harvesting}

A major reason for the failure of rainwater harvesting projects and the slow adoption of rainwater harvesting techniques is the poor selection of suitable sites and the matching of the practice with its technical and socio-economic requirements (Oweis et al., 1998). A major knowledge gap exists concerning the identification of 
those parts of the drylands in which the chances for the positive effects and adoption of rainwater harvesting techniques are high and to which further studies could be targeted (De Pauw et al., 2006). Therefore, there is a need for robust methodology that enables the assessment of the potential for rainwater harvesting and to identify areas that are suitable for this technique (Makhamreh, 2011; Mbilinyi et al., 2007; Patrick, 1997). The methodology should identify rainwater harvesting requirements based on criteria judged by experts, but should also consider that these could be changed if conditions are changed. The use of GIS will facilitate iterative process to account for these changes until optimum results are reached.

Many researchers have used GIS and remote sensing to locate sites suitable for macro-catchment rainwater harvesting schemes (De Winnaar et al., 2007; Ould Cherif Ahmed et al., 2007; Sekar and Randhir, 2007; De Pauw et al., 2006; Bodhankar, 2004; Durga Rao and Bhaumik, 2003; Oweis et al., 1998; Patrick, 1997). However few examples are found in the literature regarding the suitability for on-farm micro-catchment (less than $1000 \mathrm{~m}^{2}$ ) rainwater harvesting (Mwenge Kahinda et al., 2009; Mbilinyi et al., 2007; De Pauw et al., 2006).

For relatively small areas, a field survey carried out by experienced people will be the best technique to select the appropriate sites and to determine the suitable methods for rainwater harvesting. For larger areas the application of geographic information system (GIS) and remote sensing could be the most relevant means (Makhamreh, 2011; De Pauw et al., 2007; Prinz et al., 1998). However, planning for large scale implementation requires quantitative information and knowledge of the spatial distribution of the land characteristics-data which are often unavailable for arid environments (Prinz et al., 1998). The traditional soil survey maps at small scales do not provide the necessary information. A soil map with a large scale $(1: 10,000)$ gives sufficiently accurate information to create an acceptable suitability map for rainwater harvesting. However, these detailed maps usually cover very limited areas, and producing them is costly and time consuming. Hence, an alternative approach is required.

The objective of this study was to develop a methodology to identify the suitability of land units for different rainwater harvesting techniques in arid watersheds, based on field investigations, participatory GIS approach to integrate some socio-economic aspects and with the participation of the community.

\section{Materials and Methods}

\section{Description of the Study Area}

The research site, named Mharib, is located in the eastern part of Amman district in Jordan between latitudes $31^{\circ} 39^{\prime}$ and $31^{\circ} 43^{\prime}$ North and longitudes $36^{\circ} 12^{\prime}$ and $36^{\circ}$ $18^{\prime}$ East (Figure 1). The watershed has an area of approximately $60 \mathrm{~km}^{2}$. This watershed is a Benchmark Watershed that represents the arid area (al badia) that was selected to integrate the rainwater harvesting techniques within the agro-pastoral systems in a sustainable manner. This watershed is used to develop and test rainwater harvesting systems with the participation of rural communities (Ziadat et al., 2006).

The area lies within the xeric-aridic transitional moisture regime where the annual rainfall ranges between 100 and $150 \mathrm{~mm}$ (Jordan transitional al badia). The major geological formation is very finely dissected limestone, chert, and marl. 


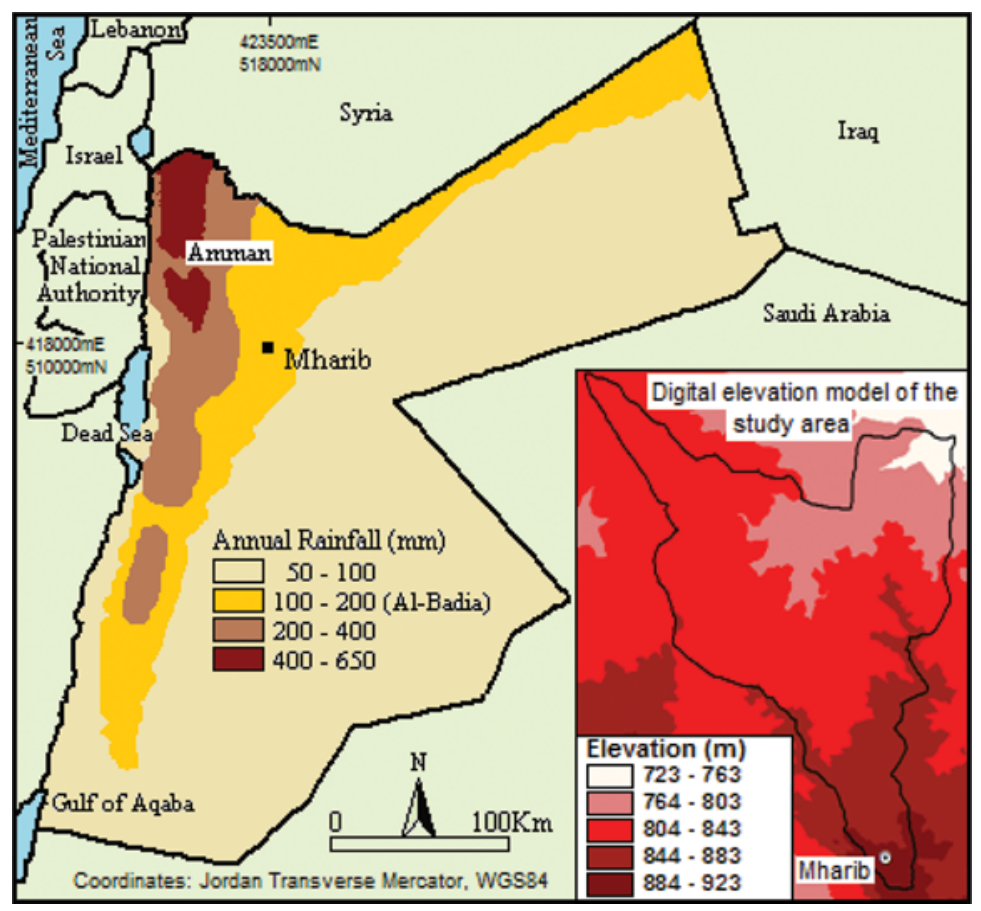

Figure 1. Location of the study site (Mharib watershed) within the Jordanian transitional al badia. (Figure available in color online.)

The soils are highly calcareous and weakly saline, characterized by high silt content, hard crust, and weak aggregation on the surface layer. They are classified as Xerochreptic Haplocambids and Haplocalcids (MoA, 1995). About 75\% of the study area has shallow soils $(<50 \mathrm{~cm})$ and slope gradients less than $12 \%$. The remaining part of the study area has medium deep and deep soils ranging between 50 and $140 \mathrm{~cm}$. Rock outcrops cover $10 \%$ of the study area (MoA, 1995). The elevation ranges between 676 and $925 \mathrm{~m}$ above sea level. The watershed is characterized by highly degraded steppe vegetation, while barley is grown in the valley bottom and along the slopes where the moisture from the limited rainfall is augmented by run-off from the hill slopes. Barley and uncultivated land are the main land cover/land use types in the area. The dominant natural vegetation species are Anabasis syriaca Iljin and Poa bulbosa L. The natural vegetation cover is degraded due to cultivation, over-grazing, and wood cutting.

The study started with assessing land suitability for rainwater harvesting using different GIS approaches and then integrates that with land tenure information and finally integrates farmers' opinions to arrive at an optimum selection of promising sites for implementation. The results were verified using expert judgment after visiting random sites as well as the farmers' appraisal of the relevancy of the outputs. The following sections explain this approach.

\section{Requirements for Rainwater Harvesting}

The criteria used to determine the requirements of different rainwater harvesting interventions were slope, soil depth, soil texture, vegetation cover, stoniness of the 


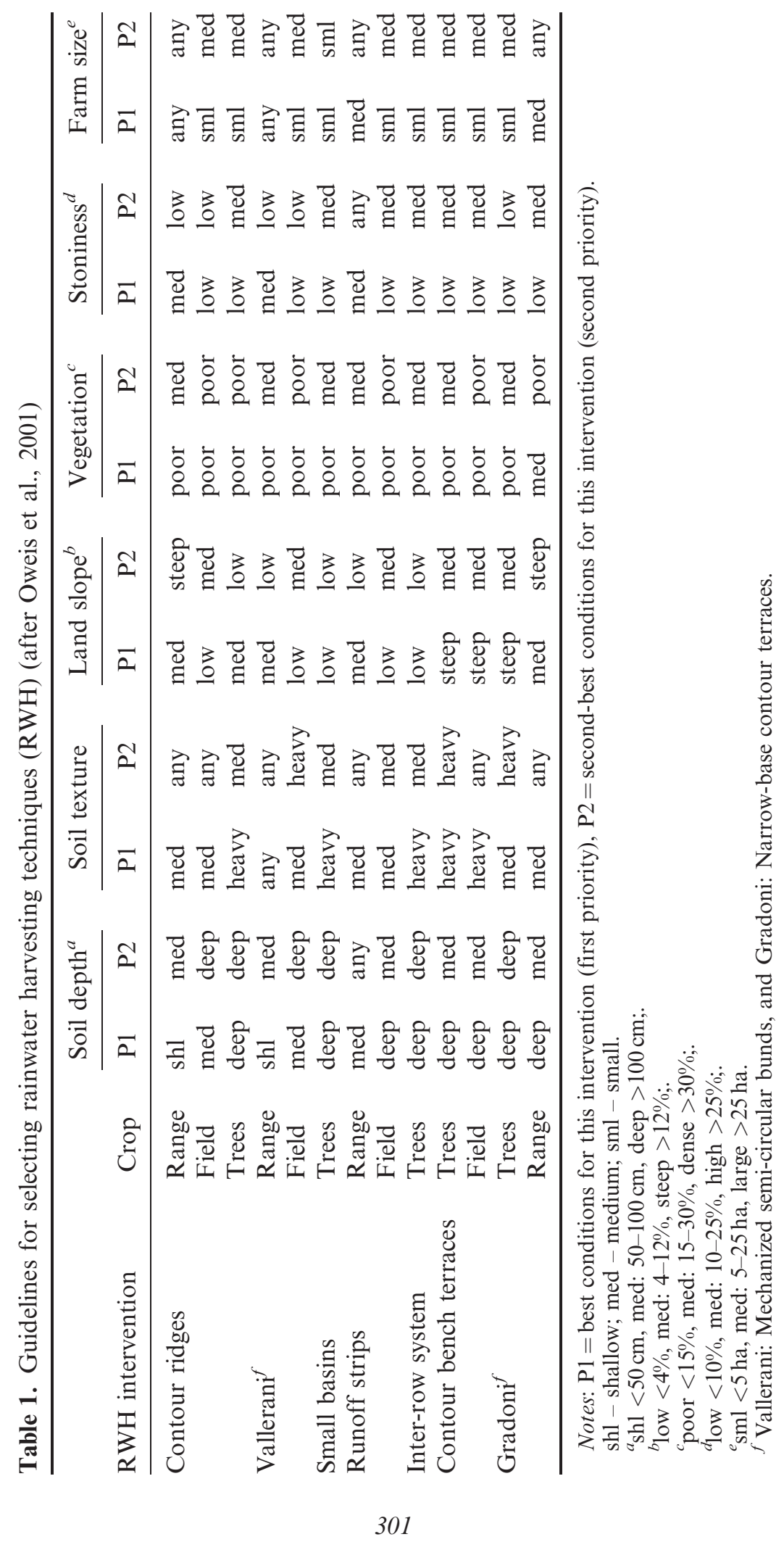


soil surface, and farm-size (Oweis et al., 2001). Slope control the amount of runoff harvested and therefore the type of rainwater harvesting. Each rainwater harvesting requires certain amount of runoff and/or the amount of excess runoff it can handle without damage. Soil depth and soil texture determine the amount of water the soil profile can store and consequently the rooting depth. High water holding capacity is needed for survival of crops because rainfall is sporadic. Vegetation cover and stoniness are indicators of the potential of land to support rainwater harvesting. Rainfall is a key criterion but because rainfall is almost uniform over the study area, it was not considered here. Discussions among a multi-disciplinary team of researchers (specialists in agronomy, water harvesting, range, hydrology, GIS, livestock, soil, land resource management, and socio-economics) lead to some modifications of these criteria. For each criterion there were two ratings identified as the "best" and "second best" options. This was meant to provide more flexibility when determining the suitability of an intervention, which allows for the incorporation of socio-economic factors at a later stage. For example, if the land is suitable for three different interventions, the land user could select one of them based on his or her preference and needs. The final criteria that were agreed upon by the multi-disciplinary team of researchers are summarized in Table 1.

\section{Characterization of Land Units}

The data required for the biophysical characterization of the watershed were partly obtained from available data and from a dedicated field survey. Contour lines, stream lines and some spot heights were extracted from topographic maps (scale 1:50,000). A digital elevation model (DEM) with a resolution of $20 \mathrm{~m}$ was generated from the contour lines and spot heights. The root mean square of error (RMSE) of the derived DEM, calculated using spot heights was $2.2 \mathrm{~m}$.

A slope map was derived from the DEM. The ArcGIS standard command (SLOPE) was used to derive the slope grid. A $3 \times 3$ average (smoothing) filter was applied to clean the layer of very small slope units. The grid was then converted into polygons to be used as land mapping units in the subsequent analyses. Slope units derived from this step were used as basic land mapping units for the suitability analysis.

The absence of detailed soil data is a common problem in arid areas. A field survey was designed to provide information on the relevant biophysical factors in the watershed. Samples were collected using a combination of two methods of sampling - free sampling and grid sampling. Grids composed of uniformly sized cells $(500 \mathrm{~m}$ by $500 \mathrm{~m})$ were used. One field observation was taken from each grid cell. To avoid a non-representative site being sampled, the surveyor was free to select the best site within each cell. This would also ensure that the various conditions within the watershed were sampled by distributing the sampling evenly across the grids. This avoids sampling bias by enforcing the sampling according to grid system. The location of the sampling points was recorded with a GPS. The total number of sampling sites was 268 (4.5 observations $/ \mathrm{km}^{2}$ ), 160 observations were used to derive the suitability maps and 108 were used to check the accuracy of the maps. The following parameters were recorded for each field observation: surface cover of stones (percentage stoniness), vegetation type and coverage (visual estimation during November), texture of the soil surface horizon (estimated by feeling), soil depth $(\mathrm{cm})$ (boreholes by digging small "chisel pits" to a depth of 40 to $50 \mathrm{~cm}$ and then use auger to reach the maximum depth, rock or large stones). 
To predict a value for unmeasured location and to produce continuous surface, the measured values of the surrounding observations was used. Closest observations should have more influence on the predicted value. Thus, the inverse distance weighted (IDW) interpolator of ArcGIS 9.3 Spatial Analyst was used to produce a continuous surface (grid file) of soil depth, stone percentage, soil texture, and vegetation cover. Stoniness and vegetation could be derived from air photo interpretation. However, since texture and soil depth could be observed only in the field, it was decided that all attributes will be collected in the field. The interpolated values were classified according to the classes listed in Table 1 to facilitate the comparison of rainwater harvesting requirements with land characteristics of each map unit (pixel). For example, the values of stone percent that were generated directly after the interpolation process were classified into three classes (low $<10 \%$, medium: $10-25 \%$, and high $>25 \%$ ) using the re-classify command in ArcGIS.

Two approaches were followed to interpret these layers and to produce suitability map. The first is a raster-based analysis by assigning a suitability class to each pixel $\left(400 \mathrm{~m}^{2}\right)$ after comparing the rainwater harvesting requirements (Table 1) with land characteristics for that pixel using arithmetic map algebra (IF-statements). This approach assigns a suitability class for each pixel. The second is polygon-based analysis where the average value of each land characteristic within each slope unit (union analysis) is calculated and then compared with the rainwater harvesting requirement to classify each slope unit. This approach assigns a suitability class for each slope mapping unit. The suitability maps derived from the two approaches were verified using 108 independent, randomly distributed sets of field observations.

\section{Biophysical Suitability for Rainwater Harvesting Interventions}

The criteria listed in Table 1 were applied to each characterized slope unit or pixel. The maximum limitation method was applied to assign suitability class, i.e., if all conditions are good for certain rainwater harvesting intervention except one condition, the final suitability is based on that limiting factor. In the case of polygon-based analysis, the result is a table with a row for each mapping unit and a number of columns that represent combinations of different rainwater harvesting interventions, each with different crop types (trees, field crops, and range species). In the case of raster-based analysis, the result is a grid for each rainwater harvesting intervention. To provide more alternatives to the farmers, two options were considered - best and second-best. In each column (in the case of polygon-based analysis) and for each grid (in the case of raster-based analysis), the mapping units suited to the relevant intervention were marked with the symbol S1 (suitable), while those not suited to a particular intervention were assigned the symbol NS (not suitable). However, in the final suitability assessment, only suitable classes were shown to avoid complexity of maps and to enable the selection among many rainwater harvesting options. Therefore, the final biophysical suitability map shows a number of rainwater harvesting interventions that are suitable for each mapping unit or pixel (Mbilinyi et al., 2007). From these alternatives within each mapping unit or pixel, the farmers, with the help of scientists, selected the most appropriate intervention(s) to be implemented in their fields.

The application of modern technologies is not enough to ensure successful implementation of rainwater harvesting scheme. A number of external factors, such 
as water and land rights, and other socio-economic factors, and beliefs will influence the type and function of the rainwater harvesting scheme (Prinz et al., 1998). The importance of the socio-economic factors to assess rainwater harvesting suitability were recognized by previous studies, but were not incorporated into the assessment. This has been identified as the main reason for the failure of rainwater harvesting projects (Mwenge Kahinda et al., 2008).

The biophysical suitability map was overlaid with the cadastral map to incorporate the area of the parcel as a criterion for selection, resulting in final rainwater harvesting suitability map. This is crucial for interventions that require a minimum area for successful implementation. The land parcels were classified based on their area into three classes (small ( $<5 \mathrm{ha}$ ); medium (5-25 ha); large ( $>25 \mathrm{ha})$. The classified parcels map was overlaid with the biophysical suitability map and the criterion for farm size listed in Table 1 was applied. If the rainwater harvesting intervention requires larger parcel than the one shown by the cadastral map, the land was considered as not suitable for that interventions, even if it is biophysically suitable.

\section{Results and Discussion}

\section{Biophysical Suitability for $\mathrm{RWH}$}

The interpolations for stone percentages are given in Figure 2 for the Mharib watershed. Similar interpolations were also completed for soil depth, soil texture, and vegetation cover, but are not shown here. The classes in Figure 2 represent the values of each attribute as shown in Table 1 . The overlay of these grids (after converting these to polygons) with the slope unit grid (after converting to polygons) provides a biophysical characterization of each slope unit (polygon-based overlay) while the overlay of these grids together provides a biophysical characterization of each pixel (raster-based overlay). The polygon-based overlay generated a map in which each slope map unit (polygon) is characterized in terms of all land characteristics, while the raster-based overlay generated several grids where each pixel in each grid is characterized in terms of one of these characteristics. Matching the requirements for various rainwater harvesting techniques with the characteristics of each slope unit or pixel generated the biophysical suitability map of the watershed (Figure 3). The rainwater harvesting requirements in Table 1 are criteria judged by experts. However, these could be changed, whenever there are substantial justifications, and using GIS, the suitability analysis could be repeated to arrive at optimum results.

Visual inspection of the two suitability maps in Figure 3, raster-based versus polygon-based maps, shows very high agreement between the two maps. Furthermore, the team undertook several field visits to different sites within the watershed to match the land suitability results with field suitability for various rainwater harvesting interventions. Compared with the suitability of randomly distributed 108 independent set of field observations, the accuracy of the two maps was very close, the raster-based (pixel) map was slightly better than the polygon-based map $(71 \%$ and $70 \%$, respectively). However, considering the processing time, the raster-based map consumes longer time to produce. This is because the grids need to be processed many time (depending on the number of rainwater harvesting interventions, which was 26 in this case) and then process the 26 maps to find the combination of rainwater harvesting interventions for which each pixel is best 


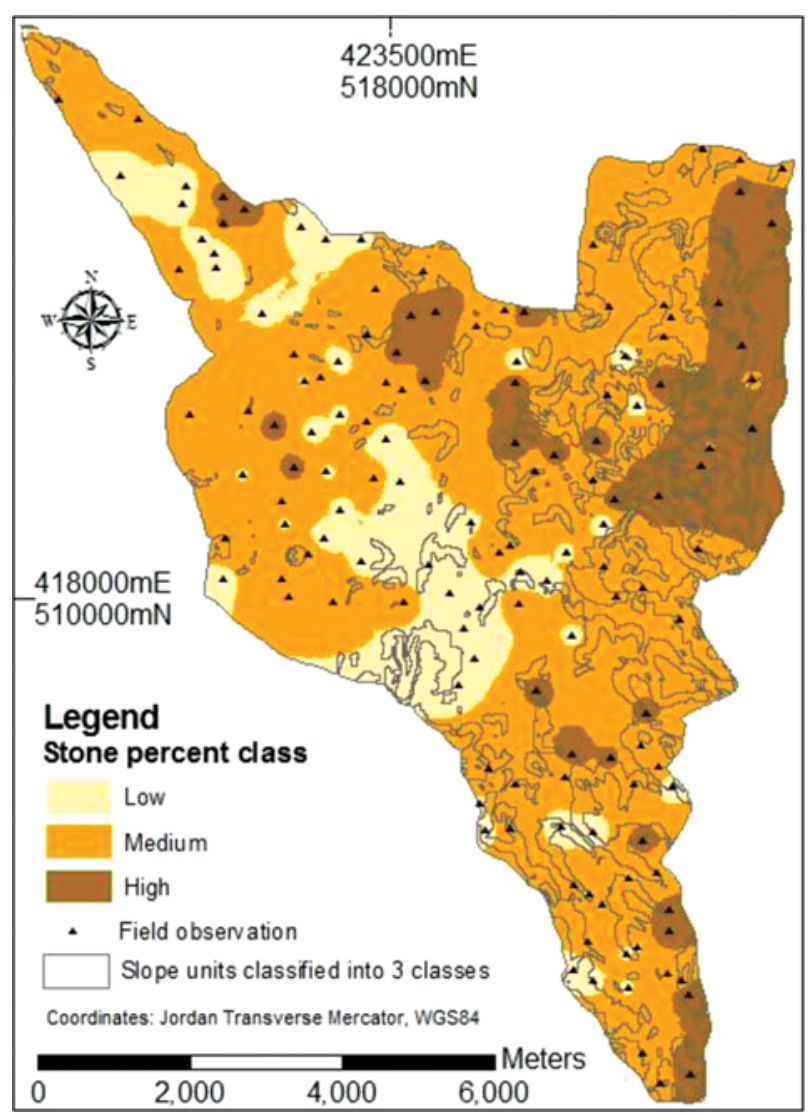

Figure 2. Surface stone cover classes (low $<10 \%$, medium 10 to $25 \%$, high $>25 \%$ ) interpolated from field observations using the inverse distance weighted (IDW) method and boundaries of slope units classified into three classes (low $<4 \%$, Medium $4-12 \%$ and steep $>12 \%$ ). (Figure available in color online.)

suitable. While dealing with slope unit (polygon) simplifies this process by producing one map that summarizes the land attributes for each map unit which can be processed in one go. Moreover, the polygon-based map showed better coincidence and match with field conditions when the boundary of each mapping unit was compared with boundaries in the field. This is because the boundaries of slope unit represent natural phenomenon that coincide much better with field variations. While boundaries delineated following the interpolation between observations is artificial because they depend solely on the distribution of field observations and the interpolation algorithm, and therefore, bear less relationship with boundaries in the reality compared with the polygon based map.

\section{Integration of Biophysical Suitability with Socio-Economic Aspects}

Land suitability evaluation is widely used by many researchers but usually without proper consideration of all stakeholders, especially the farmers. Merging multi-disciplinary technical knowledge and local experience is indispensable to 

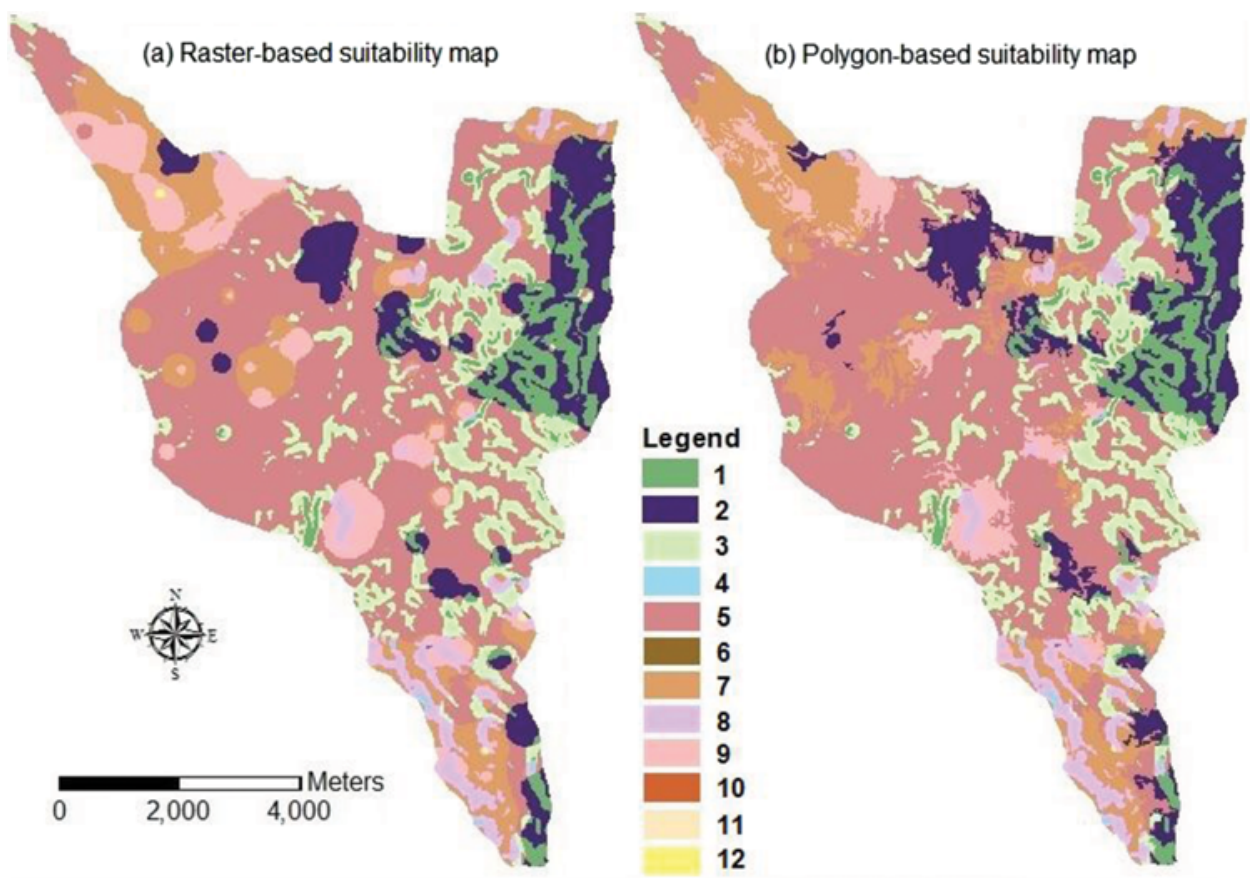

Figure 3. Potential land suitability for various rainwater harvesting options in the Mharib watershed. (1) not suitable; (2) runoff strips-range crops; (3) contour ridges-range crops, Vallerani-range crops; (4) contour bench terraces-trees or field crops, Gradoni-range crops; (5) contour ridges-range crops, Vallerani-range crops, runoff strips-range crops; (6) contour ridges-range crops, contour bench terraces-trees or field crops, Gradoni-range crops; (7) contour ridges-range crops, Vallerani-range crops, runoff strips-range or field crops; (8) contour ridges-range crops, Vallerani-range crops, runoff strips-range or field crops, contour bench terraces-trees or field crops; (9) contour ridges-range or field crops, Vallerani-range or field crops, runoff strips-range or field crops; (10) contour ridges-range crops, contour bench terraces-trees or field crops, Gradoni-trees or range crops; (11) contour ridges-trees or range or field crops, Vallerani-range or field crops, runoff strips-range or field crops, contour bench terraces-trees or field crops, Gradoni-trees or range crops; (12) contour ridges-trees or range or field crops, Vallerani-range or field crops, small basins-trees, runoff strips-range or field crops, inter row system-trees. (Figure available in color online.)

formulate sustainable land management schemes (Ahnström, et al., 2009; Malczewski, 2004). Therefore, it is important to verify the land suitability evaluation results by considering farmers' indigenous knowledge, needs and capacities, for which participatory GIS approach might provide great potential.

The suitability map was overlaid with cadastral map to apply the criterion for "farm size" (Table 1). The suitability map was updated to include this criterion. The number of alternative rainwater harvesting interventions for many mapping units was reduced as a result of applying the farm size criterion. However, these alternatives are more realistic and applicable because the final suitability depends on the biophysical as well as socio-economic criteria.

A multi-disciplinary team visited the study area. The following data were used during the visits: (1) the land suitability map for different rainwater harvesting 


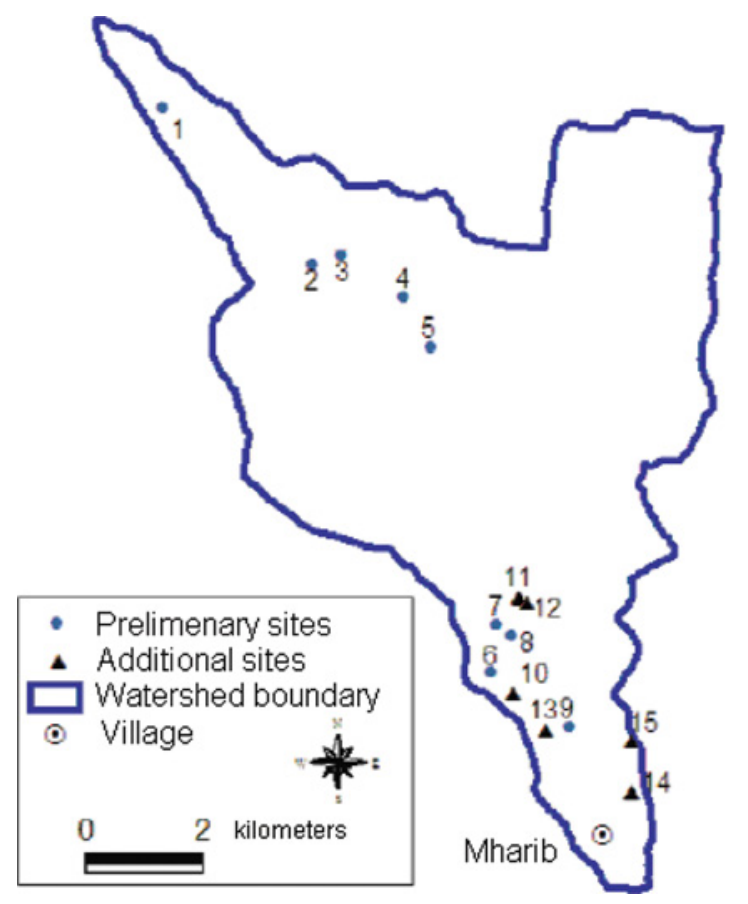

Figure 4. Locations of the sites considered for implementing rainwater harvesting by the research team (preliminary sites) and those added after consultation with the community (additional sites). (Figure available in color online.)

interventions (Figure 3); (2) information on the locations of potential earth dams and hafair (small ponds), from a separate hydrological analysis; (3) satellite images and hand-held GPS unit (used for navigation); and (4) cadastral maps. The cadastral map (provided by the Department of Land and Surveying) were used to identify the owner(s) of the land that is suitable for particular rainwater harvesting intervention(s). The socio-economic team used this information to approach the relevant owner(s) and inquire about their interest in applying the recommended rainwater harvesting interventions on their land. The team visited several sites, took notes, and made observations (preliminary sites, Figure 4). The information was then summarized and used to decide which sites should be selected, the interventions that should be applied at each site, and the priority of the selected sites for implementation.

The data collected was discussed during a meeting between the project team and 32 land owners from Mharib village. The results of this discussion are summarized in two points. First, the chance of successful implementation of interventions like earth dams and hafairs at sites which do not have communities nearby is limited. Such sites should be eliminated from further consideration. This decision includes the first five sites considered in Figure 4. Even though these sites were rated as being highly suitable from a biophysical point of view, the absence of a community living near them would limit their use and maintenance and, therefore, threaten their sustainability. The community indicated that it is impractical to move their herds to benefit from the water reservoirs. They also indicated that some other herders might use it but 
without contributing to maintenance costs due to absence of protection. It is not possible to suggest an optimum distance between rainwater harvesting structure and the community because each community might suggest different distance. Therefore, a combination of biophysical and socio-economic appraisal seems indispensible to ensure the selection of an optimum site. Relying totally on either biophysical suitability or farmers' opinion are both, individually is insufficient. Second, the project needed to collect information about the owners of sites deemed to have potential as a first step in the actual implementation of rainwater harvesting interventions. For potentially suitable sites, discussions were held with 23 owners about implementing the technique. According to expert judgment, the rainwater harvesting interventions listed in Table 1 are the most relevant and potentially suitable for this area. For each rainwater harvesting intervention, there is one or more $\operatorname{crop}(\mathrm{s})$ to be cultivated successfully. This gives the farmers some flexibility to choose rainwater harvesting that is suitable for the crop type they wish to grow.

Some of the sites selected as potentially suitable were excluded from the study because their owners did not want to participate in the project. The integration of both biophysical and socio-economic aspects to determine the potential for rainwater harvesting is vital to ensure sustainability and success. Other sites were excluded because their owners did not live in the area (absentee owners). The list of owners, derived from the cadastral map, was checked with a few farmers and the village leader (Mukhtar) who know the land owners in that village very well and they decided on names of owners who are not living in the area. A large number of land parcels were owned by people who have never lived in that area. The area is considered as one for investment with outsiders buying the land, which complicates development of the area.

\section{Farmers' Empowerment to Select Suitable Sites}

Another approach was followed when visiting the lands of those people who live in the area and own land and who had indicated their willingness to participate in the project. The biophysical suitability of their fields for the proposed interventions was assessed using the suitability maps and consequently, 18 more sites were added to those considered in Figure 4. These sites were added because in the first selection not all suitable sites were considered. After consultation with farmers, these additional sites were considered. The initial discussion was held with 32 , out of those 23 own the suitable land, more farmers joined later to make the number of farmers 41. This highlights the importance of community participation. These are marked as additional sites (Figure 4). Users can click on any location on the map to know the suitable rainwater harvesting option(s) as well as the name of the owner and the area of land parcel. Similarly, the users can enquire based on the name of the owner(s) to know the suitable rainwater harvesting option(s) for his/her land (even if he/she owns more than one piece of land within that area). This iterative and participatory approach gave the farmers the opportunity to state their needs while, at the same time, assessing the biophysical suitability of their land, which is an effective way to gain more involvement and participation from the local community. Moreover, areas with high potential for rainwater harvesting from biophysical point of view were identified and checked in the field and could be used in the future to extend the area of implementation. 
Ultimately, all sites which were selected according to this process were judged to be both biophysically and socio-economically suitable for implementing rainwater harvesting intervention(s) and to have a high chance of success. The project's technical team undertook data collection and detailed surveys at these sites, in order to design and implement various interventions. Within two years, four types of rainwater harvesting interventions were implemented in the fields of 41 farmers (total area of 62.9 hectares) in close collaboration with local community. The Vallerani rainwater harvesting technique (mechanized semi-circular bunds) was implemented in 17 fields (43.4 ha), contour ridges in 18 fields (14.5 ha), runoff strips in six fields $(5.0 \mathrm{ha})$. Water productivity $\left(\mathrm{kg} / \mathrm{m}^{3}\right)$, measured during the 2006 and 2007 season, was affected by spacing of the rainwater harvesting interventions and land slope but was generally four times higher for fields with Vallerani rainwater harvesting technique as compared with untreated fields. Furthermore, soil erosion was reduced five folds on the fields with Vallerani technique compared with fields without rainwater harvesting interventions (Oweis et al., 2011).

\section{Conclusions}

A system for identifying the potential suitability of land for different types of rainwater harvesting interventions at the watershed-level was developed. The approach matched rainwater harvesting requirements with the biophysical conditions of the land and was effective in identifying the location and the appropriate type(s) of rainwater harvesting interventions. The accuracy of raster-based and polygon-based maps was very close $(71 \%$ and $70 \%)$ and the suitability derived from both maps indicated good coincidence with suitability on the ground. However, the boundaries of suitability units derived from the polygon-based map, using slope units as suitability mapping units, indicated better coincidence with the spatial distribution in the field. Furthermore, the processing time needed to produce suitability maps was shorter in the case of polygon-based approach (slope units). Therefore the use of slope units to represent the distribution of suitability classes for rainwater harvesting and to simplify the variability of land characteristics is recommended in areas where detailed soil maps are not available.

The implementation of rainwater harvesting interventions increased the water productivity $\left(\mathrm{kg} / \mathrm{m}^{3}\right)$ four-folds and reduced soil-water erosion five-folds compared to fields without rainwater harvesting interventions. The successful and sustainable implementation of rainwater harvesting interventions in this research is attributed to the effectiveness of the approach followed to select suitable sites for rainwater harvesting through the integration of biophysical and socio-economic aspects. The iterative nature, the capabilities of participatory GIS approach, and the empowerment of local communities are indispensable features of this approach.

The results demonstrate how participatory GIS approach can be used to identify potential areas that are suitable for implementing new land-use alternatives within reasonable cost and time. The approach was also successful in integrating biophysical and socio-economic criteria into the selection process to develop sustainable interventions that improve water productivity and halt land degradation in the arid rangeland environment. The approach is applicable to similar areas within the arid regions where rainwater harvesting plays a crucial role in sustainable water and land resources management. 


\section{References}

Ahnström, J., J. Höckert, H. L. Bergeå, C. A. Francis, P. Skelton, and L. Hallgren. 2009. Farmers and nature conservation: What is known about attitudes, context factors and actions affecting conservation? Renewable Agriculture and Food Systems 24: 38-47.

Bodhankar, N. 2004. Application of vectors for suitability of landforms in siting surface water harvesting structures. Journal Environmental Geology 44: 176-179.

Critchley, W., C. Reij, and A. Seznec. 1992. Water harvesting for plant production. Vol II: Case studies and conclusions for Sub-Saharan Africa. World Bank Technical Paper Number 157. Washington, DC, World Bank, p. 134.

De Pauw, E., T. Oweis, and J. Youssef. 2007. Assessment of potential water harvesting by integrating expert knowledge in GIS methodology and a case study in Syria. (ICARDA), Aleppo, Syria. P. 41.

De Pauw, E., T. Oweis, J. Youssef, and N. Bashar. 2006. Assessing biophysical potential for water harvesting at national and global scales. 18th World Congress of Soil Science July 9-15, 2006. Philadelphia, Pennsylvania, USA.

De Winnaar, G., G. P. W. Jewitt, and M. Horan. 2007. A GIS-based approach for identifying potential runoff harvesting sites in the Thukela River basin, South Africa. Physics and Chemistry of the Earth 32: 1058-1067.

Durga Rao, K. H. V., and M. K. Bhaumik. 2003. Spatial expert support system in selecting suitable sites for water harvesting structures - a case study of Song watershed, Uttaranchal, India. Geocarto International 18(4): 43-50.

Food, and Agricultural Organization of the United Nations (FAO). 1983. Guidelines: Land evaluation for rainfed agriculture. FAO Soils Bulletin, vol. 52. FAO, Rome.

Haddad, N. 2006. Characteristics of the steppe in WANA with an emphasis on Jordan, pp. 13-39, in T. Oweis, B. Benli, A. Bruggeman and H. Farahani, eds., Characteristics of Benchmark Research Agroecosystems in WANA: Rainfed, Irrigated, and Marginal Drylands. ICARDA, Aleppo, Syria.

Hamadeh, S. K., R. Zurayk, F. Al Awar, S. Talhouk, D. Abi Ghanem, and M. Abi Said. 1999. Farming system analysis of drylands agriculture in Lebanon: an analysis of sustainability. Journal of Sustainable Agriculture 15(2/3): 33-43.

Livingstone, I. 1985. Pastoralism: An overview of practice, process, and policy. Study Prepared for FAO. ODG, Norwich.

Makhamreh, Z. 2011. Using remote sensing approach and surface landscape conditions for optimization of watershed management in Mediterranean regions. Physics and Chemistry of the Earth, Parts A/B/C 36(5-6): 213-220.

Malczewski, J. 2004. GIS-based land-use suitability analysis: A critical overview. Progress in Planning 62(1): 3-65.

Mbilinyi, B. P., H. F. Tumbo, S. D. Mahoo, and F. O. Mkiramwinyi. 2007. GIS-based decision support system for identifying potential sites for rainwater harvesting. Physics and Chemistry of the Earth 32(15-18): 1074-1081.

Ministry of Agriculture, Jordan (MoA). 1995. The Soils of Jordan. Report of the National Soil Map and Land Use Project, Undertaken by Ministry of Agriculture, Huntings Technical Services Ltd., and European Commission. Level One, Level Two, Level Three and JOSCIS Manual. Ministry of Agriculture, Amman, Jordan.

Mwenge Kahinda, J., E. S. B. Lillie, A. E. Taigbenu, B. Taute, and R. J. Boroto. 2008. Developing suitability maps for rainwater harvesting in South Africa. Physics and Chemistry of the Earth Parts A/B/C 33(8-13): 788-799.

Mwenge Kahinda, J., A. E. Taigbenu, B. B. P. Sejamoholo, E. S. B. Lillie, and R. J. Boroto. 2009. A GIS-based decision support system for rainwater harvesting (RHADESS). Physics and Chemistry of the Earth Parts A/B/C 34(13-16): 767-775.

Ould Cherif Ahmed, A., R. Nagasawa, K. Hattori, D. Chongo, M. F. Perveen. 2007. Analytical hierarchic process in conjunction with GIS for identification of suitable sites 
for water harvesting in the Oasis areas: case study of the Oasis zone of Adrar, Northern Mauritania. Journal of Applied Sciences 7(19): 2911-2917.

Oweis, T., B. Benli, A. Bruggemen, and H. Farahani, eds. 2006. Characteristics of benchmark research agroecosystems in WANA: rainfed, irrigated, and marginal drylands. International Center for Agricultural Research in the Dry Areas, Aleppo, Syria.

Oweis, T., M. Karrou, and F. Ziadat. 2011. Community-Based Optimization of the Management of Scarce Water Resources in Agriculture in Central and West Asia and North Africa Project (Water Benchmarks of CWANA). Final Report, Badia Benchmark and satellite sites. International Center for Agricultural Research in the Dry Areas, Aleppo, Syria.

Oweis, T., A. Oberle, and D. Prinz. 1998. Determination of potential sites and methods for water harvesting in Central Syria, pp. 83-88, in H-P. Blum, H. Eger, E. Fleischauer, A. Hebel, C. Reij, and K. G. Steijner, eds., Towards Sustainable Land Use Vol. 1. Advances in Geoecology 31. Catena Verlag, Reiskirchen, Germany.

Oweis, T., D. Prinz, and A. Hachum. 2001. Water harvesting: indigenous knowledge for the future of the drier environments. International Center for Agricultural Research in the Dry Areas, Aleppo, Syria. 40 pp. ISBN 92-9127-116-0.

Oweis, T., and A. Taimeh. 1996. Evaluation of a small basin water-harvesting system in the arid region of Jordan. Water Resources Management 10: 21-34.

Patrick, E. 1997. Assessing water harvesting suitability, in Proceedings of the International Workshop Remote Sensing and Water Resources, November-December 1995. Food and Agriculture Organization of the United Nations. Montpellier, France.

Prinz, D., T. Oweis, and A. Oberle. 1998. Rainwater harvesting for dry land agriculture developing a methodology based on remote sensing and GIS, in Proceedings of the XIII. International Congress Agricultural Engineering, 2-6 February, ANAFID, Rabat, Morocco.

Reynolds, J. F., and D. M. S. Smith. 2007. Global desertification: Building a science for dryland development. Science 316(5826): 847-851.

Sankari, M. 1993. Maintenance and development of rangeland in eastern Arabic countries, pp. 180-297, in M. S. Radwan, ed., Workshop on Maintenance and Development of the Rangeland, Its Role in Combating Desertification of the Arab World. Food and Agricultural Organization of the United Nations, Amman, Jordan.

Sekar, I., and T. O. Randhir. 2007. Spatial assessment of conjunctive water harvesting potential in watershed systems. Journal of Hydrology 334(1-2): 39-52.

Taimeh, A. Y. 1989. Soils of Muwaqqar. University of Jordan, Amman.

Taimeh, A. Y., and B. I. Hattar (Eds.). 2001. Improvement of Agricultural Productivity in the Arid and Semi-arid Zones of Jordan (JAZZP). A cooperative project between the Ministry of Agriculture and the European Union. Vol. 1. Main report. University of Jordan.

Tewari, V. P., and A. Ranjana. 2005. Degradation of arid rangelands in Thar Desert, India: A review. Arid Land Research and Management 19: 1-12.

Tsubo, M., S. Walker, and M. Hensley. 2005. Quantifying risk for water harvesting under semi-arid condition. Part I. Rainfall intensity generation. Agricultural Water Management 76: 77-93.

Van Wesemael, B., J. Poesen, A. Sole Benet, L. Cara Barrionuevos, and J. Puigdefabregas. 1998. Collection and storage of runoff from hill slopes in semi-arid environments: geomorphic and hydrologic aspects of the Aljibe system in Almeria Province, Spain. Journal of Arid Environments 40: 1-14.

Ziadat, F., T. Oweis, S. Mazahreh, A. Bruggeman, N. Haddad, E. Karablieh, B. Benli, M. Abu Zanat, J. Al-Bakri, and A. Ali. 2006. Selection and characterization of badia watershed research sites. International Center for Agricultural Research in the Dry Areas, Aleppo, Syria. 